\title{
The Control of Oxidation-Induced Intergranular Embrittlement by Grain Boundary Engineering in Rapidly Solidified Ni-Fe Alloy Ribbons
}

\author{
Shin-ichi Yamaura ${ }^{1}$, Sadahiro Tsurekawa ${ }^{2}$ and Tadao Watanabe ${ }^{2, *}$ \\ ${ }^{1}$ Institute for Materials Research, Tohoku University, Sendai 980-8577, Japan \\ ${ }^{2}$ Laboratory of Materials Design and Interface Engineering, Department of Nanomechanics, Graduate school of Engineering, \\ Tohoku University, Sendai 980-8579, Japan
}

The relation between grain boundary microstructure and oxidation-induced intergranular embrittlement has been investigated in rapidly solidified and subsequently annealed $\mathrm{Ni}-39$ mass $\% \mathrm{Fe}$ thin ribbons with different grain boundary microstructures. These thin ribbons were heated in air under different tensile stresses to enhance intergranular oxidation. Oxidation-induced embrittlement was then evaluated by three-point bending tests. It was found that the brittleness of oxidized ribbons varied according to the grain boundary microstructure. Fine-grained microstructure was found to be superior to coarse-grained one by suppressing oxidation-induced embrittlement when the type and the frequency of grain boundaries (that is called the Grain Boundary Character Distribution, GBCD) were properly controlled. Moreover, for a given grain size, grain boundary microstructure containing higher frequencies of special boundaries was shown to be advantageous in the control of oxidationinduced intergranular embrittlement. On the basis of these findings, the importance and usefulness of grain boundary engineering for the control of oxidation-induced intergranular embrittlement are discussed.

(Received April 7, 2003; Accepted June 9, 2003)

Keywords: grain boundaries, intergranular oxidation, stress accelerated grain boundary oxidation, grain boundary character distribution, grain boundary engineering

\section{Introduction}

Polycrystalline materials often suffer from oxidation and corrosion during heat-treatment, hot-working and service in air or reactive environments at high temperatures in the case that extremely deep penetration of oxidation along grain boundaries can take place inside the materials. ${ }^{1-4)}$ Such oxidation morphology is termed "intergranular oxidation" or "grain boundary oxidation". Intergranular oxidation is particularly detrimental to the strength of polycrystalline materials at high temperatures. Excellent high-temperature strength and oxidation resistance are required for high performance high-temperature materials. Accordingly the control of intergranular oxidation is an important subject in grain boundary engineering. For instance, it was recently pointed out that interfacial oxidation played an important role in processing of semi-conducting devices ${ }^{5)}$ and that fatigue failure started from intergranular oxides in carburized steel. ${ }^{6}$

It is well known that the formation of oxide scale, particularly the penetration of oxidation along grain boundaries can be strongly enhanced by an applied stress. ${ }^{7-11)}$ This phenomenon is termed "Stress-Accelerated Grain Boundary Oxidation" (hereafter denoted as SAGBO). ${ }^{10)}$ Mino et al. reported that the extent of SAGBO in Inconel 617 was quite different from boundary to boundary, and they suggested that the relative orientation relationship between two adjoining grains changed the structure and the oxidation resistance of a grain boundary. ${ }^{9)}$ Moreover, Brumm et al. pointed out that intergranular oxidation was observed along only certain grain boundaries in Ni-Al alloy. ${ }^{4)}$ From these observations, it is very likely that the extent of intergranular oxidation depends on the grain boundary character. We previously studied the relationship between the extent of intergranular oxidation and the grain boundary character in $\mathrm{Ni}-39$ mass $\%(40$ at $\%) \mathrm{Fe}$

*To whom all correspondence should be addressed. alloy. It was found that low $\Sigma$ CSL boundaries (particularly $\Sigma 3,11,19$ and 27) showed high oxidation resistance and that the classification of grain boundaries in terms of CSL relationships was useful to distinguish the propensity to oxidation among individual grain boundaries. ${ }^{12)}$

Grain boundary engineering has been proposed to bridge the gap between the basic knowledge of physical, chemical and mechanical properties of individual grain boundaries and the bulk properties of polycrystalline materials by quantitative evaluation of the grain boundary microstructure, such as the Grain Boundary Character Distribution (hereafter denoted as GBCD), the grain boundary connectivity, the grain size, the grain size distribution and the grain orientation distribution. ${ }^{13)}$ It was found that grain boundary engineered Alloy 600 was drastically strengthened against creep resistance at high temperatures by increasing the frequency of CSL boundaries. ${ }^{14)}$

As mentioned above, bulk properties of polycrystalline materials can be controlled to some extent by manipulating the grain boundary microstructure. Therefore, the problem of oxidation-induced embrittlement may be overcome by controlling the grain boundary microstructure in polycrystalline materials. The objective of this work is to prove that the oxidation-induced intergranular embrittlement could be controlled by manipulating grain boundary microstructures in $\mathrm{Ni}-39$ mass\% Fe based on the nickel-iron binary alloy system for high temperature materials.

Recently, rapid solidification has been recognized as one of the most powerful techniques to endow a material with a new or novel property through the control of grain boundary microstructure. ${ }^{15)}$ Watanabe et al. have studied the microstructures of rapidly solidified $\mathrm{Fe}-6.5$ mass $\% \mathrm{Si}$ ribbons with bcc crystal structure, and showed that the grain orientation distribution and the GBCD in the rapidly solidified ribbon were greatly changed by subsequent annealing in different conditions and that a drastic improvement in ductility of the 
ribbons was achieved by the introduction of a sharp texture and a high frequency of special boundaries. ${ }^{16,17)}$ Therefore, the rapid solidification technique was applied to the preparation of the specimens with different grain boundary microstructures.

\section{Experimental}

An ingot of $\mathrm{Ni}-39$ mass $\% \mathrm{Fe}$ alloy (originally prepared as $\mathrm{Ni}-40$ at $\% \mathrm{Fe}$ ) was produced by vacuum melting, and machined into a rod. Table 1 gives the detailed chemical composition of the $\mathrm{Ni}-39$ mass\%Fe alloy used for rapid solidification. A newly designed nozzleless and twin-roller type rapid solidification equipment was used in order to avoid contamination of the alloy by contacting the nozzle. ${ }^{18)} \mathrm{A}$ droplet of the alloy melted and electromagnetically levitated in the center of a radio frequency induction spiral coil was flowed down into the gap between rotating twin rollers and rapidly solidified into a ribbon in pure Ar gas atmosphere.

Rapidly solidified thin ribbons of about $100 \mu \mathrm{m}$ thickness were produced at roll speeds of $14.1 \mathrm{~m} / \mathrm{s}$ and $28.3 \mathrm{~m} / \mathrm{s}$. Tapeshaped specimens, $5 \mathrm{~mm} \times 25 \mathrm{~mm}$ in dimension, were stamped out from the as-solidified ribbons by a spark cutting machine. The grain boundary microstructures of ribbon specimens were analyzed quantitatively by a Field EmissionScanning Electron Microscope-Electron Backscattering Pattern/Orientation Imaging Microscope (hereafter denoted as FE-SEM-EBSP/OIM) system after annealing in a vacuum of $10^{-3} \mathrm{~Pa}$ at $1073-1473 \mathrm{~K}$. Then, the analyzed specimens were oxidized at $1073-1200 \mathrm{~K}$ for $18-24 \mathrm{~h}$ in air at a constant load (10-14 MPa). After the oxidation treatment, the specimens were fractured by a three-point bending test at room temperature. The distance between the two supporting points was $8 \mathrm{~mm}$. The relationship between the grain boundary microstructure and the observed fracture characteristics was examined.

\section{Results and Discussion}

\subsection{Preparation of rapidly solidified and subsequently annealed specimens}

We prepared five distinct specimens having different grain boundary microstructures. Four types of the specimens were rapidly solidified at the roll speed of $28.3 \mathrm{~m} / \mathrm{s}$. One of them was used without subsequent annealing (RS1 with the grain size of $2 \mu \mathrm{m}$ ) and other three were subsequently annealed for $1 \mathrm{~h}$ at $1073 \mathrm{~K}, 1273 \mathrm{~K}$ and $1473 \mathrm{~K}$ for grain growth and for controlling the fraction of special boundaries (RSA1, RSA2 and RSA3 with the grain size of about 3.5, 30 and $50 \mu \mathrm{m}$, respectively). Another one which was produced at the roll speed of $14.1 \mathrm{~m} / \mathrm{s}$ to obtain larger grains, was used without subsequent annealing (RS2 with a grain size of about $3.5 \mu \mathrm{m})$. The grain size of each specimen was measured by the FE-SEM-EBSP/OIM system. In the present work, subboundaries and twin-boundaries were regarded as individual grain boundaries.

The grain boundary character distributions, GBCDs and the averaged grain sizes are given in Table 2. In the series of annealing, we obtained three distinct specimens that had different grain sizes but almost the same GBCD (the frequency of special boundaries being as high as about $70 \%$, particularly about $60 \%$ twin $(\Sigma 3)$ boundaries) (RSA1, RSA2 and RSA3). We prepared three sets of each specimen (RSA1-1-3, 2-1-3, 3-1-3 and RS1-1-3). Furthermore, when the roll speed was lowered to $14.1 \mathrm{~m} / \mathrm{s}$, the as-solidified specimen RS2-1 had a grain size of about $3.5 \mu \mathrm{m}$ and the frequency of CSL boundaries of about $40 \%$. By comparing the two specimens of RSA1 and RS2, we could clarify the dependence of intergranular embrittlement on the GBCD at almost the same grain size.

The OIM micrographs showing the grain and grain boundary configuration of each specimen are indicated in Fig. 1. In these figures, a red line denotes a $\Sigma 1$ (low angle) boundary, a green line corresponds to a $\Sigma 3$ (twin) boundary and other colored lines to higher $\Sigma$-CSL boundaries. A black line denotes a random boundary (R). In Fig. 1, there are many twins in annealed specimens. The grain size of the specimens rapidly solidified at the roll speed of $28.3 \mathrm{~m} / \mathrm{s}$ was increased by annealing (see Figs. 1(a)-(d) for RS1-1, RSA1-1, 2-1 and 3-1). The higher the annealing temperature, the larger the grain size was obtained. In the case of this alloy with fcc crystal structure, a large number of twins were formed in annealed ribbons because of the low stacking fault energy. None of the annealed ribbons showed any sharp texture due to the introduction of an extremely large number of twin boundaries by annealing as reported by Lin et al. ${ }^{19}$ )

Table 1 Detailed compositions (mass\%) of the alloy used in this study.

\begin{tabular}{cccccccccccc}
\hline $\mathrm{Ni}$ & $\mathrm{Fe}$ & $\mathrm{Co}$ & $\mathrm{Mn}$ & $\mathrm{Cu}$ & $\mathrm{Mg}$ & $\mathrm{Al}$ & $\mathrm{C}$ & $\mathrm{P}$ & $\mathrm{S}$ & $\mathrm{Si}$ & \\
\hline Bal. & 39.0 & 0.009 & $<0.001$ & $<0.001$ & $<0.001$ & $<0.004$ & 0.0001 & 0.00078 & 0.0007 & 0.0007 & \\
\hline
\end{tabular}

Table 2 Sample designation and the characteristics of the grain boundary microstructure in rapidly solidified and subsequently annealed $\mathrm{Ni}-39$ mass $\% \mathrm{Fe}$ alloy ribbons used in this study.

\begin{tabular}{|c|c|c|c|c|c|c|c|c|}
\hline \multirow{3}{*}{$\begin{array}{l}\text { Processing } \\
\text { designation }\end{array}$} & \multirow{3}{*}{$\begin{array}{c}\text { Rapid solidification } \\
\text { roll speed } \\
(\mathrm{m} / \mathrm{s})\end{array}$} & \multirow{2}{*}{\multicolumn{2}{|c|}{$\begin{array}{l}\text { Annealing } \\
\text { subsequent }\end{array}$}} & \multicolumn{5}{|c|}{ Grain boundary microstructure } \\
\hline & & & & \multirow{2}{*}{$\mathbb{C}_{(\mu \mathrm{m})}^{\text {Grain size }}$} & \multicolumn{4}{|c|}{ Grain boundary character distribution (\%) } \\
\hline & & Temp. (K) & Time (h) & & Low angle & $\Sigma 3$ (Twin) & $\Sigma 5-\Sigma 29$ & Random \\
\hline RS1 & 28.3 (3600r.p.m.) & - & - & 2 & 5.1 & 24.7 & 7.4 & 62.8 \\
\hline RSA1 & 28.3 & 1073 & 1 & 3.5 & 1.1 & 53.8 & 12.1 & 33.0 \\
\hline RSA2 & 28.3 & 1273 & 1 & 30 & 2.3 & 60.7 & 8.5 & 28.5 \\
\hline RS2 & 14.1 (1800r.p.m.) & - & - & 3.5 & 4 & 28 & 7 & 61 \\
\hline
\end{tabular}



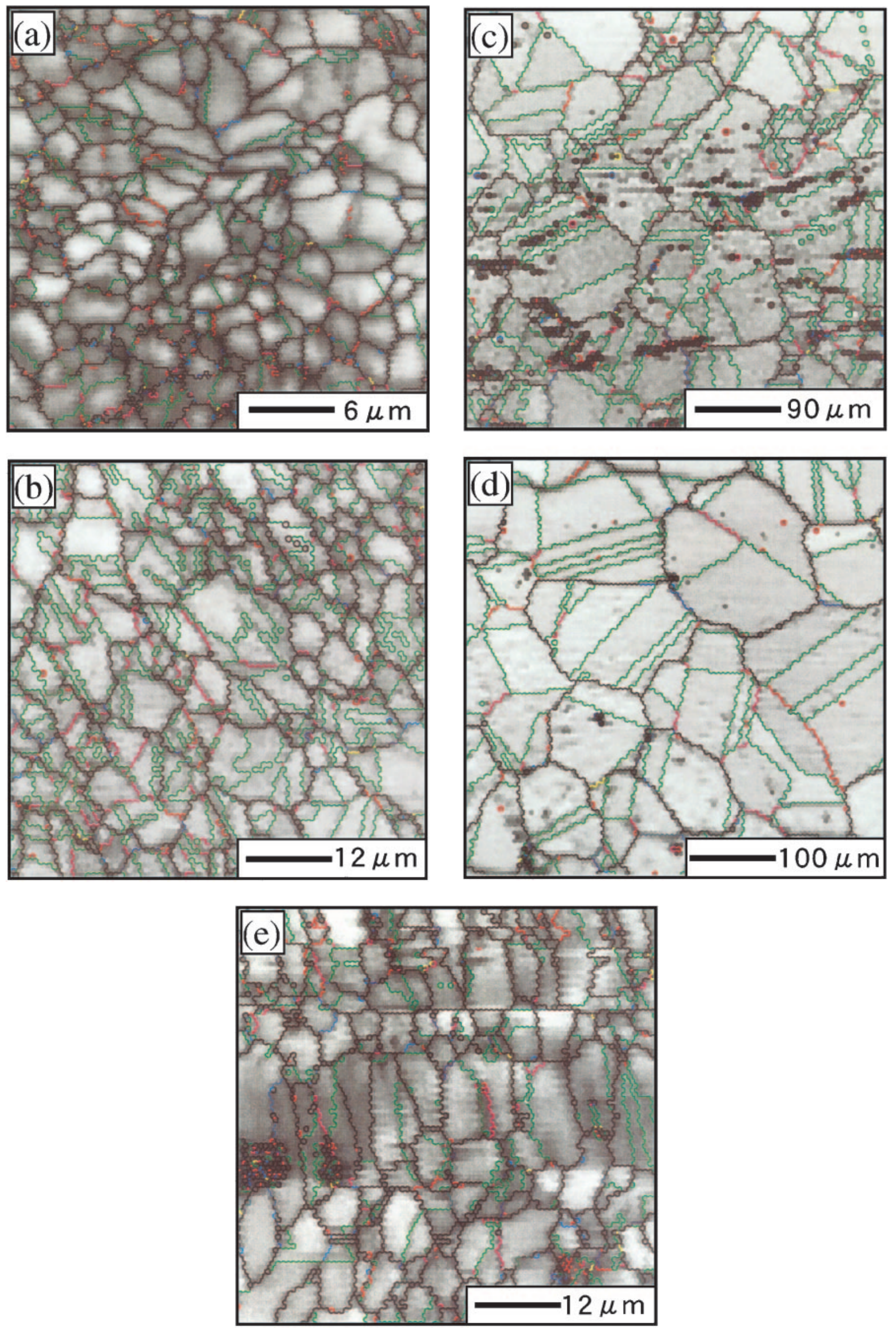

Fig. 1 OIM maps of grain boundary microstructure for studied specimens rapidly solidified at a roll speed of $28.3 \mathrm{~m} / \mathrm{s}$ and subsequently annealed. (a) as-solidified ribbon; (b), (c) and (d) ribbons annealed for $1 \mathrm{~h}$ at $1073 \mathrm{~K}, 1273 \mathrm{~K}$ and $1473 \mathrm{~K}$, respectively. Specimen shown in (e) was solidified at $14.1 \mathrm{~m} / \mathrm{s}$. (a) is obtained from the specimen RS1-1; (b) RSA1-1; (c) RSA2-1; (d) RSA3-1 and (e) RS2-1. 

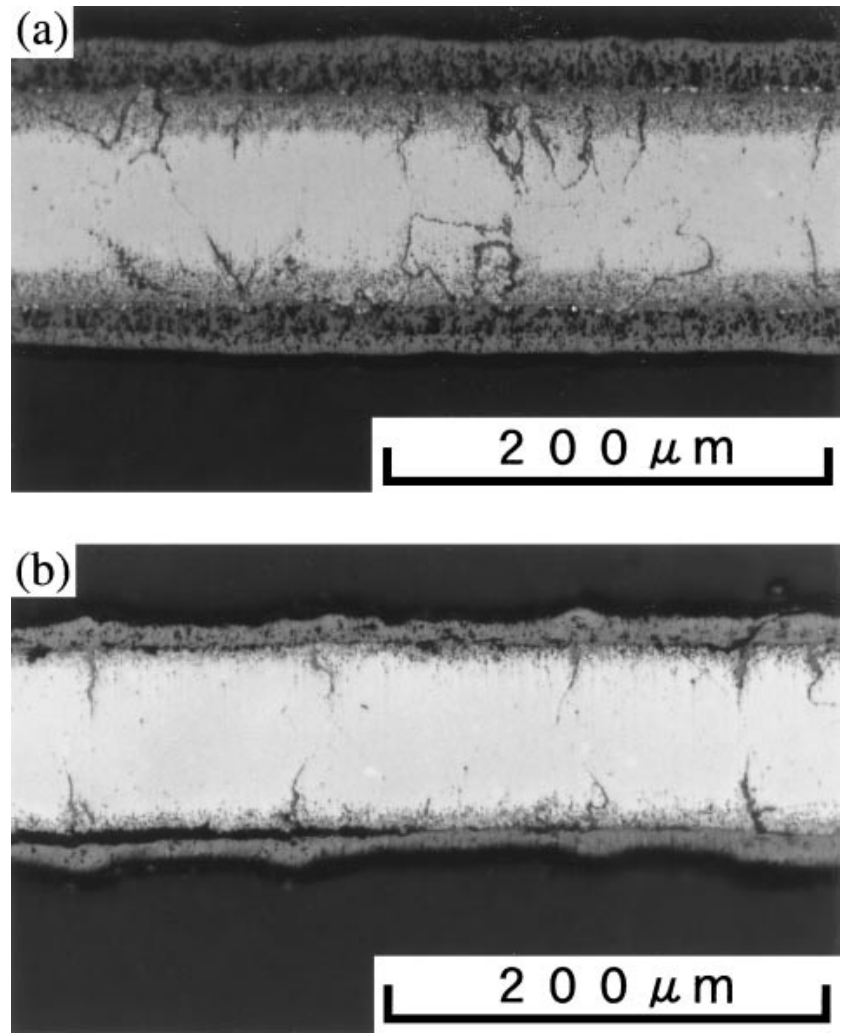

Fig. 2 Intergranular oxidation observed at cross-section of the specimens (the grain size of $50 \mu \mathrm{m}$ ) oxidized at $1073 \mathrm{~K}$ for $25 \mathrm{~h}$ in air. (a) the specimen oxidized under the tensile stress of $14 \mathrm{MPa}$ and (b) the specimen oxidized without stress.

\subsection{Observation of stress-accelerated grain boundary oxidation (SAGBO)}

Figures 2(a) and (b) show optical micrographs of the specimens oxidized at $1073 \mathrm{~K}$ for $25 \mathrm{~h}$ in air (a) with and (b) without the tensile stress of $14 \mathrm{MPa}$, respectively. The average grain size of the specimens was about $50 \mu \mathrm{m}$. These figures clearly show that the applied stress accelerated intergranular oxidation. The two possible mechanisms for SAGBO have been proposed; ${ }^{8)}$ i) the acceleration of grain boundary diffusion of reactant atoms and/or ii) the exposure of internal matrix due to the formation of microcracks in oxide scale. The SAGBO effect observed in this alloy probably came from these reasons.

3.3 Effect of grain boundary microstructure on creep deformation during oxidation-induced intergranular embrittlement

The effect of tensile stress on oxidation-induced intergranular embrittlement was studied by creep tests under a constant tensile load and subsequent three-point bending tests for a series of specimens (RSA1, 2, 3, RS1 and RS2).

Figures 3(a) and (c) show the creep curves for the specimens with different grain boundary microstructures in air at $1073 \mathrm{~K}$ and at a tensile stress of $14 \mathrm{MPa}$. Figure 3(b) shows the creep curves of the specimens in air at $1200 \mathrm{~K}$ and at a tensile stress of $10 \mathrm{MPa}$. The displacement during heating up to $1073 \mathrm{~K}$ or $1200 \mathrm{~K}$ corresponds to the thermal expansion of tensile jigs. Although the specimen RS1-2 with a grain size of about $2 \mu \mathrm{m}$ was prematurely fractured, oxidation was
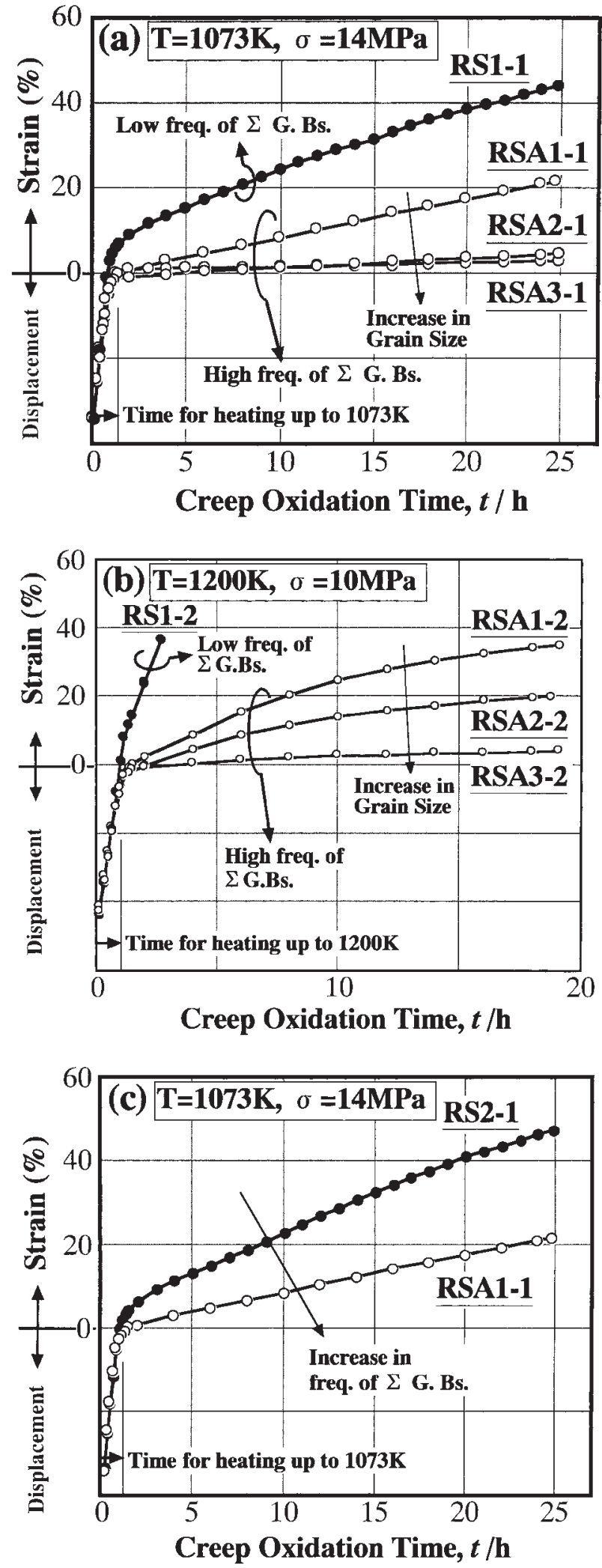

Fig. 3 The creep curves for the specimens obtained by creep oxidation test (a) at $1073 \mathrm{~K}$ for $24 \mathrm{~h}$ in air under the stress of $14 \mathrm{MPa}$; (b) at $1200 \mathrm{~K}$ for $18 \mathrm{~h}$ in air under the stress of $10 \mathrm{MPa}$ including the results for the specimens, RS1-1, RSA1-1, 2-1 and 3-1 to study the difference of strain depending on grain size; (c) at $1073 \mathrm{~K}$ for $24 \mathrm{~h}$ in air under the stress of $14 \mathrm{MPa}$ including the results for the two specimens, RSA1-1 and RS2-1 to study the effect of GBCD on the strain. 
continued to $18 \mathrm{~h}$. We can examine the effect of grain size on the oxidation-creep strain from Figs. 3(a) and (b), and the effect of the GBCD from Fig. 3(c). In Figs. 3(a) and (b), the largest creep strain is observed for the as-solidified specimen RS1 having the smallest grain size and the lowest frequency of CSL boundaries among other specimens studied. The creep strain in the specimens RSA1, 2 and 3, where the GBCDs were almost the same, decreased with increasing the grain size. This is probably because creep deformation was controlled by grain boundary sliding, and therefore the total creep strain of a specimen can change depending on the density of grain boundaries at a constant GBCD. Figure 3(c) demonstrates the effect of GBCD on the strain of the specimens. The creep resistance was found to increase with increasing the frequency of $\Sigma$-GBs, which was consistent with the previous report by Thaveeprungsriporn et al. for Alloy 600. ${ }^{14)}$

Three points bending tests were performed subsequently for oxidized samples in order to examine the effect of tensile stress on intergranular oxidation embrittlement. Figures 4(a) and (b) present an optical micrograph and a schematic illustration, respectively, showing intergranular cracks observed in an oxidized specimen after the bending test. The external oxide scale around the intergranular cracks was exfoliated owing to deformation of specimen during the bending test. It is clearly shown in the figures that the cracks
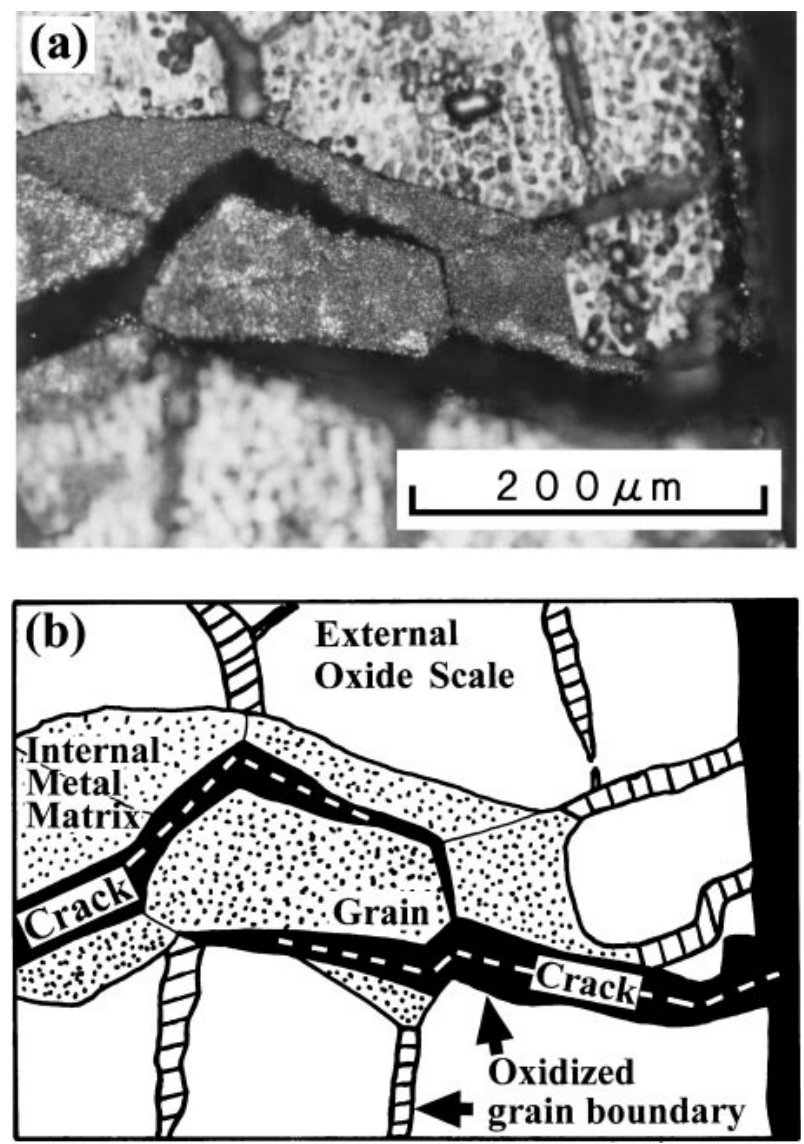

Fig. 4 (a) An optical micrograph of fractured part in the oxidized specimen after the three points bending test. (b) A schematic illustration of the intergranular cracks observed in (a). Specimens used in the present work fractured intergranularly and showed severe brittleness. can propagate along oxidized grain boundaries. Most of the oxidized specimens showed brittle fracture caused by intergranular oxidation as seen in Fig. 4.

\subsection{Effect of grain boundary microstructure on oxida- tion-induced intergranular embrittlement}

\subsubsection{The evaluation of oxidation-induced intergranular embrittlement}

After creep-oxidation test, the specimens were heavily oxidized and the thick oxide scale was grown. It was thus impossible to measure the specimen thicknesses after oxidation. Therefore, we assume that elongation causes a reduction in the thickness of a specimen deformed in tension, without taking account of the surface damage by oxidation. The bending strength of a thin ribbon can be estimated as follows. The maximum fiber stress from the 3-points bending test can be obtained by,

$$
\sigma_{\max }=\frac{3 w l}{2\left(\frac{1}{\varepsilon+1}\right)^{2} a^{2} b}
$$

where $w$ is the load needed to fracture the specimen, $l$ the distance between two supporting points, $a$ and $b$ the thickness and the width of the specimen before the creep oxidation test, respectively, $\varepsilon$ the tensile strain of the specimen during the creep test. Assuming that crack initiation always occurs at an oxidized grain boundary on the tensile side of a thin specimen at a constant fracture stress, the following equation is given from eq. (1).

$$
\begin{aligned}
\sigma_{\max , \mathrm{A}}=\sigma_{\max , \mathrm{B}} & =\frac{3 w_{\mathrm{A}} l}{2\left(\frac{1}{\varepsilon_{\mathrm{A}}+1}\right)^{2} a_{\mathrm{A}}^{2} b_{\mathrm{A}}} \\
& =\frac{3 w_{\mathrm{B}} l}{2\left(\frac{1}{\varepsilon_{\mathrm{B}}+1}\right)^{2} a_{\mathrm{B}}^{2} b_{\mathrm{B}}} \\
\therefore w_{\mathrm{B}} & =\frac{\left(\varepsilon_{\mathrm{A}}+1\right)^{2} a_{\mathrm{B}}^{2} b_{\mathrm{B}}}{\left(\varepsilon_{\mathrm{B}}+1\right)^{2} a_{\mathrm{A}}^{2} b_{\mathrm{A}}} w_{\mathrm{A}}
\end{aligned}
$$

The suffix A means the standard specimen among a series of specimens and $\mathrm{B}$ means other studied specimens. The value of $w_{\mathrm{A}}$ is the fracture load for the standard specimen $\mathrm{A}$, and $w_{\mathrm{B}}$ the estimated load required to fracture the specimen $\mathrm{B}$. Here we should emphasize that the difference in the grain boundary microstructure of each specimen is not taken into account in $w_{\mathrm{B}}$. Accordingly, the relative fracture strength, $w_{\text {exp }} / w_{\mathrm{B}}$ suggests the influence of grain boundary microstructure on oxidation-induced embrittlement since the practical fracture load $w_{\text {exp }}$ of each specimen is strongly affected by the grain boundary microstructure. The experimental data obtained from the specimens are also tabulated in Tables 3, 4 and 5. We have previously reported the maximum fiber stress, $\sigma_{\max }$ and the estimated relative strength of oxidized specimens, $w_{\exp } / w_{\mathrm{B}} \cdot{ }^{20)}$ We modified the equations to perform more strict estimation. So, we obtained more significant effect of controlling the grain boundary microstructure on the improvement in oxidation-induced embrittlement as demonstrated in this paper. The detailed discus- 
Table 3 Results of creep oxidation test and three point bending test for the series of specimens oxidized at $1073 \mathrm{~K}$ for $24 \mathrm{~h}$ in air with the tensile stress of $14 \mathrm{MPa}$.

\begin{tabular}{|c|c|c|c|c|c|c|c|c|c|c|c|c|c|}
\hline \multirow{3}{*}{$\begin{array}{c}\text { Sample } \\
\text { designation }\end{array}$} & \multirow{3}{*}{$\begin{array}{c}\text { Grain } \\
\text { size } \\
(\mu \mathrm{m})\end{array}$} & \multicolumn{10}{|c|}{ Creep oxidation test } & \multicolumn{2}{|c|}{ Three points bending test } \\
\hline & & \multirow{2}{*}{$\begin{array}{l}\text { Stress } \\
(\mathrm{MPa})\end{array}$} & \multirow{2}{*}{$\begin{array}{l}\text { Temp. } \\
(\mathrm{K})\end{array}$} & \multirow{2}{*}{$\begin{array}{l}\text { Time } \\
\text { (h) }\end{array}$} & \multirow{2}{*}{$\begin{array}{l}\text { Gauge } \\
\text { length } \\
(\mathrm{mm})\end{array}$} & \multicolumn{2}{|c|}{ Before test } & \multicolumn{2}{|c|}{ After test } & \multirow{2}{*}{$\begin{array}{l}\text { Strain rate } \\
\qquad(\% / \mathrm{h})\end{array}$} & \multirow{2}{*}{$\begin{array}{l}\text { Total strain } \\
\qquad(\%)\end{array}$} & \multirow{2}{*}{$\begin{array}{c}\text { Practical } \\
\text { fracture load }(\mathrm{g})\end{array}$} & \multirow{2}{*}{$\begin{array}{c}\text { Relative fracture } \\
\text { strength }\end{array}$} \\
\hline & & & & & & Width & Thickness & Width & Thickness & & & & \\
\hline RS1-1 & 2 & 14 & 1073 & 24 & 8 & 5.00 & 103 & 4.92 & 130 & 1.40 & 44.0 & 86.8 & 0.76 \\
\hline RSA1-1 & 3.5 & 14 & 1073 & 24 & 8 & 5.00 & 105 & 4.95 & 125 & 0.75 & 21.5 & 167.4 & 1.00 \\
\hline RSA2-1 & 30 & 14 & 1073 & 24 & 8 & 5.00 & 100 & 4.83 & 136 & 0.23 & 4.8 & 118.3 & 0.58 \\
\hline RSA3-1 & 50 & 14 & 1073 & 24 & 8 & 5.00 & 110 & 5.00 & 136 & 0.15 & 2.9 & 157.0 & 0.61 \\
\hline RS2-1 & 3.5 & 14 & 1073 & 24 & 8 & 5.00 & 94 & 4.55 & 75 & 1.50 & 47.2 & 46.5 & 0.51 \\
\hline
\end{tabular}

Table 4 Results of creep oxidation test and three point bending test for the series of specimens oxidized at $1200 \mathrm{~K}$ for $18 \mathrm{~h}$ in air with the tensile stress of $10 \mathrm{MPa}$.

\begin{tabular}{|c|c|c|c|c|c|c|c|c|c|c|c|c|c|}
\hline \multirow{3}{*}{$\begin{array}{c}\text { Sample } \\
\text { designation }\end{array}$} & \multirow{3}{*}{$\begin{array}{l}\text { Grain } \\
\text { size } \\
(\mu \mathrm{m})\end{array}$} & \multicolumn{10}{|c|}{ Creep oxidation test } & \multicolumn{2}{|c|}{ Three points bending test } \\
\hline & & \multirow[b]{2}{*}{$\begin{array}{l}\text { Stress } \\
(\mathrm{MPa})\end{array}$} & \multirow{2}{*}{$\begin{array}{l}\text { Temp. } \\
\text { (K) }\end{array}$} & \multirow[b]{2}{*}{$\begin{array}{l}\text { Time } \\
\text { (h) }\end{array}$} & \multirow{2}{*}{$\begin{array}{l}\text { Gauge } \\
\text { length } \\
(\mathrm{mm})\end{array}$} & \multicolumn{2}{|c|}{ Before test } & \multicolumn{2}{|c|}{ After test } & \multirow{2}{*}{$\begin{array}{l}\text { Strain rate } \\
\qquad(\% / \mathrm{h})\end{array}$} & \multirow[b]{2}{*}{$\begin{array}{c}\text { Total strain } \\
\qquad \%)\end{array}$} & \multirow{2}{*}{$\begin{array}{c}\text { Practical } \\
\text { fracture load }(\mathrm{g})\end{array}$} & \multirow[b]{2}{*}{$\begin{array}{c}\text { Relative fracture } \\
\text { strength }\end{array}$} \\
\hline & & & & & & $\begin{array}{l}\text { Width } \\
(\mathrm{mm})\end{array}$ & $\begin{array}{c}\text { Thickness } \\
(\mu \mathrm{m})\end{array}$ & $\begin{array}{l}\text { Width } \\
(\mathrm{mm})\end{array}$ & $\begin{array}{c}\text { Thickness } \\
(\mu \mathrm{m})\end{array}$ & & & & \\
\hline RS1-2 & 2 & 10 & 1200 & 18 & 12 & 5.00 & 105 & 4.60 & 110 & 18.9 & 36.6 & 55.8 & 0.52 \\
\hline RSA1-2 & 3.5 & 10 & 1200 & 18 & 12 & 5.00 & 100 & 4.45 & 142 & 1.00 & 34.9 & 99.2 & 1.00 \\
\hline RSA2-2 & 30 & 10 & 1200 & 18 & 12 & 5.00 & 82 & 4.80 & 139 & 0.58 & 20.2 & 84.3 & 1.00 \\
\hline RSA3-2 & 50 & 10 & 1200 & 18 & 12 & 5.00 & 110 & 5.00 & 150 & 0.13 & 4.3 & 76.9 & 0.38 \\
\hline
\end{tabular}

Table 5 Results of creep oxidation test and three point bending test for the series of specimens oxidized at $1200 \mathrm{~K}$ for $18 \mathrm{~h}$ in air without the tensile stress.

\begin{tabular}{|c|c|c|c|c|c|c|c|c|c|c|c|c|c|}
\hline \multirow{3}{*}{$\begin{array}{c}\text { Sample } \\
\text { designation }\end{array}$} & \multirow{3}{*}{$\begin{array}{c}\text { Grain } \\
\text { size } \\
(\mu \mathrm{m})\end{array}$} & \multicolumn{10}{|c|}{ Creep oxidation test } & \multicolumn{2}{|c|}{ Three points bending test } \\
\hline & & \multirow{2}{*}{$\begin{array}{l}\text { Stress } \\
(\mathrm{MPa})\end{array}$} & \multirow{2}{*}{$\begin{array}{l}\text { Temp. } \\
\text { (K) }\end{array}$} & \multirow{2}{*}{$\begin{array}{l}\text { Time } \\
\text { (h) }\end{array}$} & \multirow{2}{*}{$\begin{array}{l}\text { Gauge } \\
\text { length } \\
(\mathrm{mm})\end{array}$} & \multicolumn{2}{|c|}{ Before test } & \multicolumn{2}{|c|}{ After test } & \multirow{2}{*}{$\begin{array}{l}\text { Strain rate } \\
\qquad(\% / \mathrm{h})\end{array}$} & \multirow{2}{*}{$\begin{array}{c}\text { Total strain } \\
(\%)\end{array}$} & \multirow{2}{*}{$\begin{array}{l}\text { Practical } \\
\text { fracture load }(\mathrm{g})\end{array}$} & \multirow{2}{*}{$\begin{array}{c}\text { Relative fracture } \\
\text { strength }\end{array}$} \\
\hline & & & & & & $\begin{array}{l}\text { Width } \\
(\mathrm{mm})\end{array}$ & $\begin{array}{l}\text { Thickness } \\
(\mu \mathrm{m})\end{array}$ & $\begin{array}{l}\text { Width } \\
(\mathrm{mm})\end{array}$ & $\begin{array}{l}\text { Thickness } \\
(\mu \mathrm{m})\end{array}$ & & & & \\
\hline RS1-3 & 2 & - & 1200 & 18 & - & 5.00 & - & 4.80 & 167 & - & - & 135.8 & 0.43 \\
\hline RSA1-3 & 3.5 & - & 1200 & 18 & - & 5.00 & - & 4.95 & 180 & - & - & 376.8 & 1.00 \\
\hline RSA2-3 & 30 & - & 1200 & 18 & - & 5.00 & - & 5.00 & 165 & - & - & 262.0 & 0.82 \\
\hline RSA3-3 & 50 & - & 1200 & 18 & - & 5.00 & - & 4.90 & 160 & - & - & 179.4 & 0.61 \\
\hline
\end{tabular}

sions are in the following.

Relative fracture strength, $w_{\exp } / w_{\mathrm{B}}$ was calculated and plotted as a function of the grain size in Fig. 5. The specimens, RSA1-1, RSA1-2 and RSA1-3, with the grain size of $3.5 \mu \mathrm{m}$, were chosen as a standard to calculate the relative fracture strength corresponding to Figs. 5(a), (b) and (c), respectively. Since the specimens oxidized without stress were not elongated, the thickness and the width of the specimens after oxidation shown in Fig. 5(c) were used for calculation.

\subsubsection{Experimental evidence for the effect of grain boundary microstructure}

(1) Grain size effect

Figures 5(a) and (b) demonstrate that the relative fracture strength increases with decreasing grain size when the GBCD is almost constant. However, a significant reduction in the relative fracture strength occurred when the frequency of special boundaries decreased. We can see that the finegrained specimen (RSA1-1) is more immune from oxidationinduced embrittlement than the coarse-grained ones, (RSA21 and 3-1). This may be because the deeply penetrating intergranular oxidation could not occur in fine-grained specimens, owing to the prevention of further oxidation at special boundaries. Recently, newly designed ultra steels which have ultra fine grain size less than one micron, have been successfully obtained. ${ }^{21)}$ Thereby we can utilize the same methodology as that in the ultra fine-grained steels to suppress the oxidation-induced intergranular embrittlement by grain refinement. Although the grain size in the specimen RS1-1 $(2 \mu \mathrm{m})$ was smaller than that in specimen RSA1-1 $(3.5 \mu \mathrm{m})$, the fracture strength of specimen RS1-1 was lower than that of specimen RSA1-1. This is because the specimen RS1-1 has the smaller grain size and the lower frequency of special boundaries than the specimen RSA1-1. Accordingly, more difficulty arises in arresting the penetration of intergranular oxidation in the specimen RS1-1.

(2) GBCD effect

As has been mentioned above, it is possible to examine the influence of the GBCD on intergranular embrittlement by comparing the results from the specimen RSA1-1 with those from the specimen RS2-1. The former with a very high frequency of special boundaries, (more than $50 \%$ of twin $(\Sigma$ 


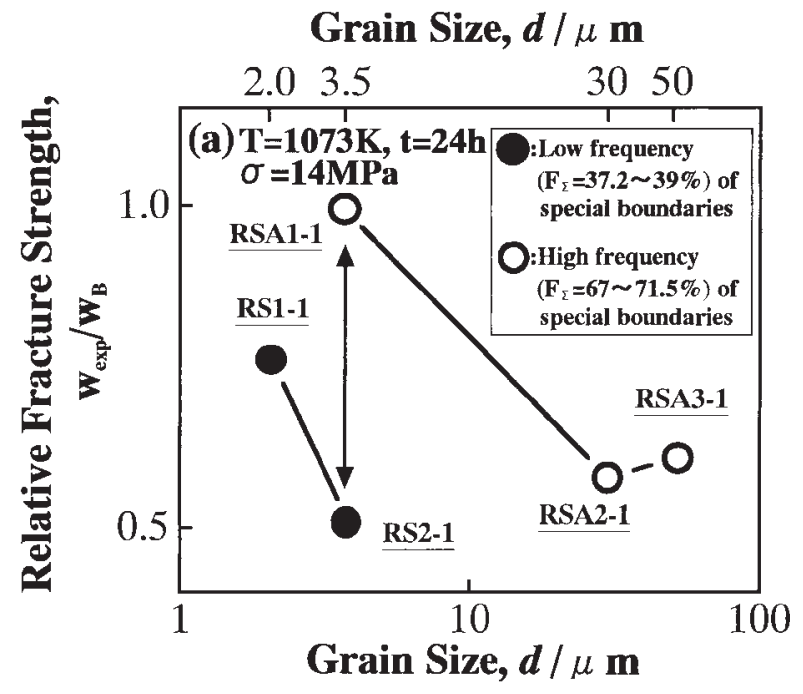

Grain Size, $d / \mu$ m

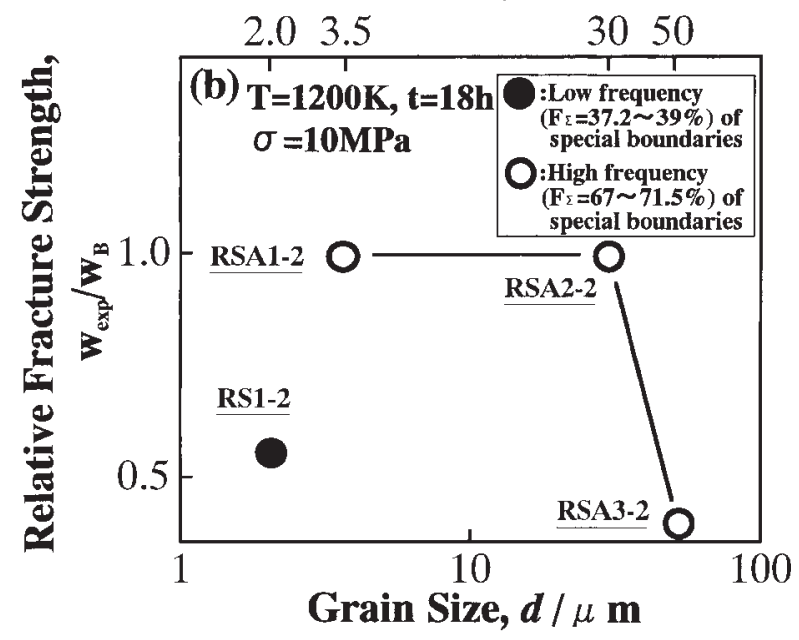

Grain Size, $d / \mu$ m

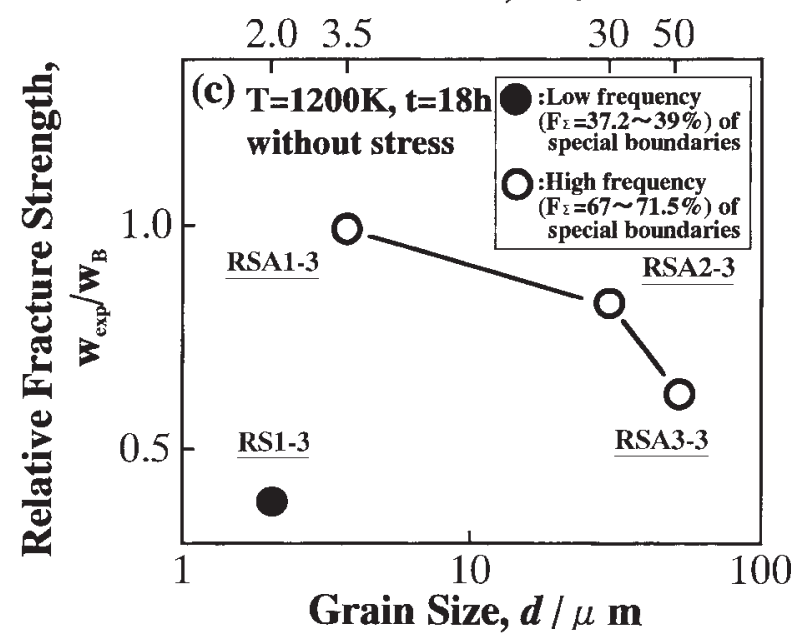

Fig. 5 The relative fracture strength of specimens oxidized at $1073 \mathrm{~K}$ for $24 \mathrm{~h}$ with the stress of $14 \mathrm{MPa}$ (a); at $1200 \mathrm{~K}$ for $18 \mathrm{~h}$ with the stress of $10 \mathrm{MPa}$ (b); and at $1200 \mathrm{~K}$ for $18 \mathrm{~h}$ without the stress (c) shown as a function of the grain size. Open circles and solid ones denote the specimens having high frequency of special boundaries $\left(\mathrm{F}_{\Sigma}=67-71.5 \%\right)$ and those having low frequency of special boundaries $\left(\mathrm{F}_{\Sigma}=37.2-39 \%\right)$, respectively.
3) boundaries), is found to be more immune from oxidationinduced embrittlement than the other specimen characterized by the relatively low frequency (39\%) of special boundaries. At any rate, it is evident that the intergranular oxidationinduced embrittlement depends on the grain boundary microstructure such as the GBCD and the grain size. A similar tendency was observed for the specimens oxidized without the applied stress as indicated in Fig. 5(c). We conclude that the fine-grained material with a high frequency of special boundaries can show a strong immunity from intergranular oxidation-induced embrittlement.

The cross-sectional views of the creep-oxidized specimens (RS1-1, 2-1 and RSA1-1, 2-1, 3-1) are shown in Fig. 6, in order to understand the reason why grain-refinement and special-boundary-enhancement are so effective and useful in improving the immunity against oxidation-induced embrittlement. Specimen, RS1-1 with the fine grain size of $2 \mu \mathrm{m}$ shown in Fig. 6(a) was elongated easily because of the finegrained microstructure including a lower frequency of special boundaries. Although deep penetration of intergranular oxidation was not observed, we can see that the region suffering from necking was heavily internal-oxidized owing to the stress concentration. On the contrary, the remarkable oxidation penetration along grain boundaries was observed in the coarse-grained specimens with the grain size of about $30 \mu \mathrm{m},(\mathrm{RSA} 2-1)$ and $50 \mu \mathrm{m},(\mathrm{RSA} 3-1)$ as shown in Figs. 6(c) and (d), respectively. It was found that the fracture strength of coarse-grained specimens was remarkably lowered by heavy intergranular oxidation although they showed small elongation during the creep tests. Those findings reveal an important practical problem that intergranular oxidation enhanced by the application of tensile stress severely degrades the fracture strength of the polycrystalline structure even if the shape and the size of the structure is little changed.

Moreover, by comparing the two specimens (RSA1-1 and RS2-1) shown in Figs. 6(b) and (e), it can be seen that the specimen having a low frequency of special boundaries (RS2-1) was deformed easily by grain boundary sliding promoting internal oxidation, which led to severe damage of the microstructure in the specimen as seen in Fig. 6(e) even if the two specimens (RSA1-1 and RS2-1) have almost the same average grain size.

\section{The Control of Oxidation-induced Intergranular Embrittlement by Optimizing Grain Boundary Microstructure}

Intergranular oxidation resistance at individual grain boundaries in a polycrystal can vary depending on the grain boundary character. In general, such special boundaries as CSL boundaries have high immunity from intergranular oxidation, as recently found by the present authors. ${ }^{12)}$ In addition, this work has revealed that the grain boundary microstructure characterized by the GBCD and grain size can significantly affect oxidation embrittlement of polycrystalline materials. We now try to solve the next problem how to engineer the network of grain boundaries, i.e. the grain boundary microstructure, controlling the overall bulk properties of polycrystalline materials. When there is a high frequency of random boundaries inter-connecting to each 

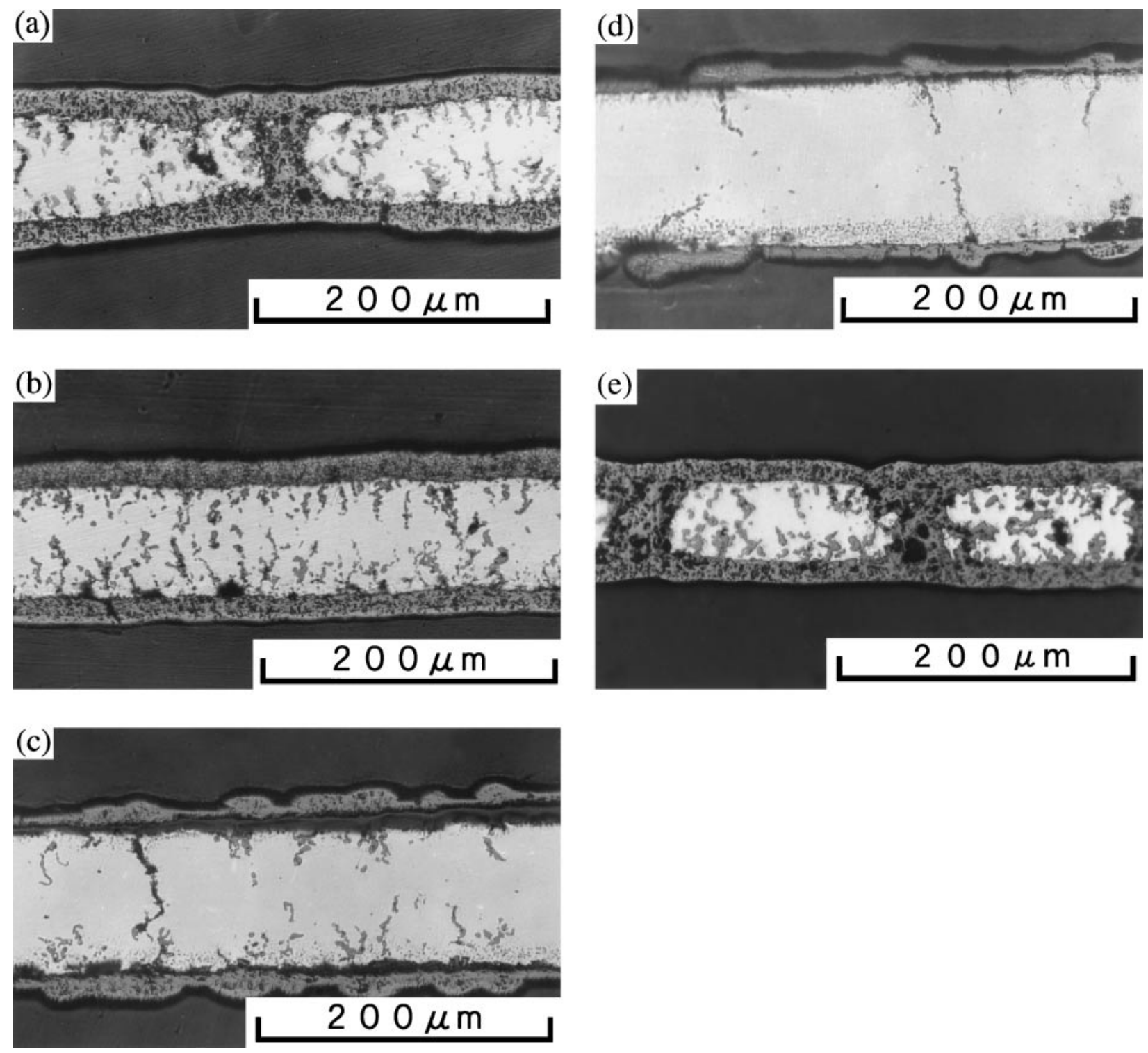

Fig. 6 Cross-sectional views of specimens oxidized at $1073 \mathrm{~K}$ for $24 \mathrm{~h}$ with the stress of $14 \mathrm{MPa}$. The specimens are (a) RS1-1; (b) RSA1-1; (c) RSA2-1; (d) RSA3-1 and (e) RS2-1. Note the change from uniform oxidation to local (intergranular) oxidation as a function of grain size in (a)-(d).

other, intergranular oxidation can take place easily and deeply along random grain boundaries preferentially. In other words, the susceptibility to intergranular oxidation penetration is strongly affected by the connecting length of random boundaries. Moreover, according to percolation theory, the percolation threshold in bond process in two-dimensional hexagonal clusters is $0.653 .^{23)}$ This means that an intergranular oxidation path traversing across a specimen can be formed if the frequency of random boundaries is more than about $65 \%$ in thin ribbons as one of the present authors pointed very early. ${ }^{24)}$ This consideration suggested that the GBCD has a significant role in engineering grain boundaries as a primary way to control the overall properties of materials as well as grain size.

Figure 7 gives a schematic illustration of structuredependent intergranular oxidation controlled by the GBCD and the grain size. It is evident that embrittlement can be suppressed in a fine-grained specimen with a high frequency of special boundaries as discussed in section 3.4 because of a high probability that intergranular oxidation can be arrested by a special boundary and/or a triple junction consisting of special boundaries. From the above discussion, the optimization of grain boundary microstructure by grain boundary engineering is indispensable for the control of high-temperature strength and oxidation-induced intergranular embrittlement.

\section{Conclusions}

The effect of grain boundary microstructures on oxidationinduced intergranular embrittlement was studied in rapidly solidified $\mathrm{Ni}-39$ mass $\% \mathrm{Fe}$ alloy ribbon. It has been found that oxidation-induced intergranular embrittlement depends on the grain size; the embrittlement is more effectively restrained in a fine-grained ribbon rather than a coarsegrained one. Furthermore, oxidation-induced intergranular embrittlement also strongly depends on the GBCD; oxidation-induced intergranular embrittlement can be controlled 


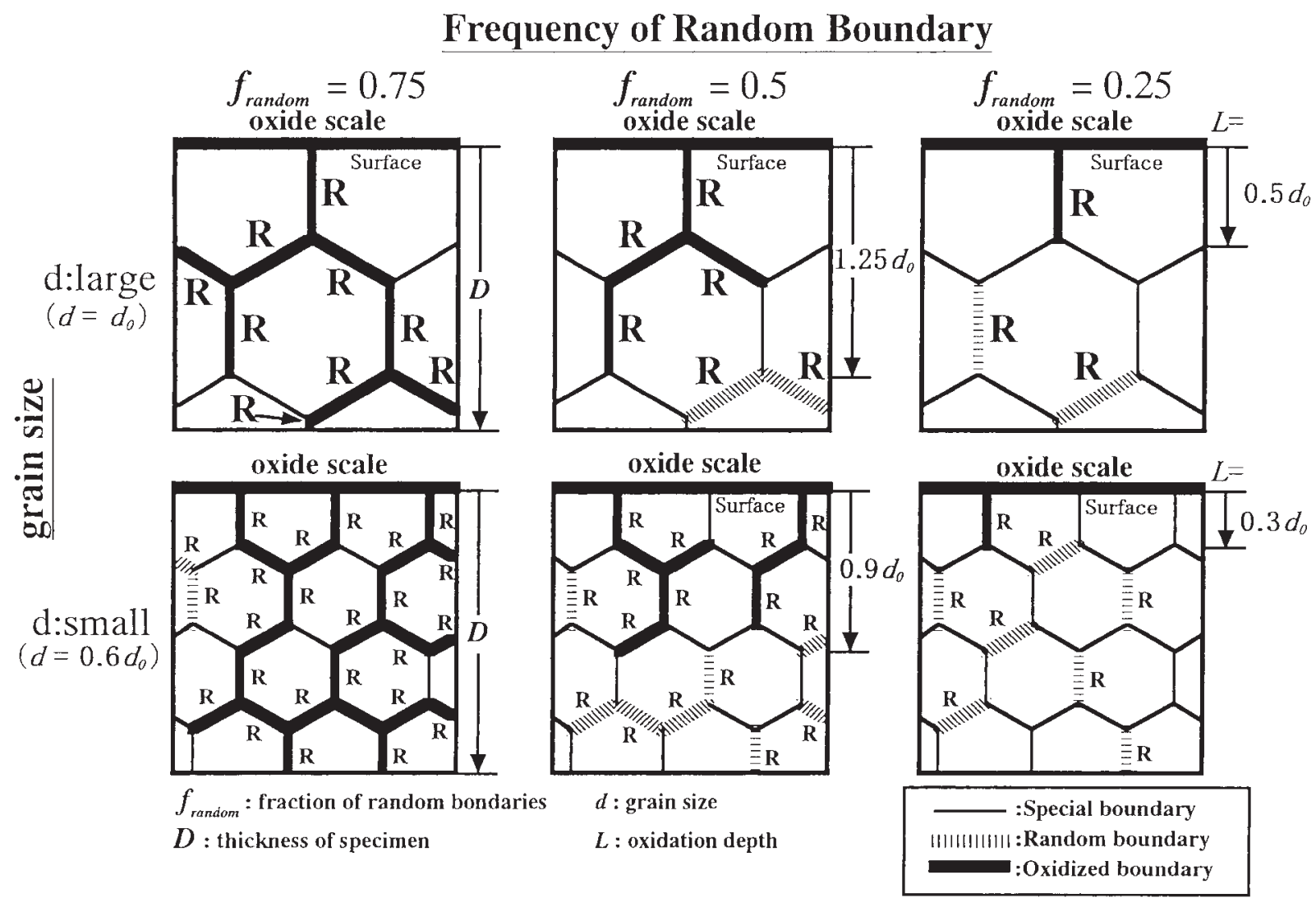

Fig. 7 A schematic illustration of structure-dependent intergranular oxidation controlled by the grain boundary microstructure (GBCD and grain size) in polycrystals.

by increasing the frequency of special boundaries possessing good immunity from oxidation. Accordingly, we conclude that the optimization of grain boundary microstructure is important for the control of oxidation-induced intergranular embrittlement in polycrystalline materials.

\section{Acknowledgements}

This work was supported by a Grant-in-Aid for Scientific Research (B)(2)(10555226) from the Ministry of Education, Culture, Sports, Science and Technology of Japan and by ISIJ Research Promotion Grant. The authors thank Prof. Y. Furuya of Hirosaki University for his help in using a rapid solidification equipment and Mr. T. Matsuzaki for technical assistance in experiments.

\section{REFERENCES}

1) Y. Shida, F. H. Stott, B. D. Bastow, D. P. Whittle and G. C. Wood: Oxid. Met. 18 (1982) 93-113.

2) Y. Shida and T. Moroishi: Corros. Sci. 33 (1992) 211-224.

3) H. C. Yi, S. W. Guan, W. W. Smeltzer and A. Petric: Acta Metall. Mater. 42 (1994) 981-990.

4) M. W. Brumm, H. J. Grabke and B. Wagemann: Corros. Sci. 36 (1994) $37-53$.

5) K. A. Koh and S. J. Chua: J. Electr. Mater. 26 (1997) 1070-1075.

6) H. Kanisawa and H. Satoh: J. Japan Society of Heat Treatment (Netsu-shori) 37 (1997) 287-292. (in Japanese)

7) C. J. McMahon and L. F. Coffin, Jr.: Metall. Trans. 1 (1970) $3443-$ 3450.

8) M. L. Sessions and C. J. McMahon, Jr.: Proc. 4th Boton Landing conference on Grain boundaries in engineering materials, ed. by J. L. Walter, J. H. Westbrook and D. A. Woodford, (Claitor's Publishing
Division, 1974) pp. 477-489.

9) K. Mino, A. Ohtomo and Y. Saiga: J. Japan Inst. Metals 44 (1980) 1397-1403. (in Japanese)

10) R. H. Bricknell and D. A. Woodford: Metall. Trans. A 12A (1981) 1673-1680.

11) K. Kusabiraki, K. Sakuradani and S. Saji: Tetsu to Hagane 84 (1998) 291-296. (in Japanese)

12) S. Yamaura, Y. Igarashi, S. Tsurekawa and T. Watanabe: Acta Mater. 47 (1999) 1163-1174.

13) T. Watanabe: Res Mechanica 11 (1984) 47-84.

14) V. Thaveeprungsriporn and G. S. Was: Metall. Mater. Trans. A 28A (1997) 2101-2112.

15) T. Watanabe: Texture and Microstructure 20 (1992) 195-216.

16) T. Watanabe, H. Fujii, H. Oikawa and K. I. Arai: Acta Metall. 37 (1989) 941-952.

17) T. Watanabe, K. I. Arai, K. Yoshimi and H. Oikawa: Philos. Mag. Lett. 59 (1989) 47-52.

18) Y. Furuya: in Proc. 1st Japan-France Intelligent Materials and Structures Seminar, Institute of Fluids Science, ed. by J. Tani and P. F. Gobin (Oct. Sendai, Japan) (1997) pp. 113-117.

19) P. Lin, G. Palumbo and K. T. Aust: Scr. Mater. 36 (1997) 1145-1149.

20) S. Yamaura, Y. Igarashi, S. Tsurekawa and T. Watanabe: Properties of Complex Inorganic Solids 2, ed. by A. Meike, A. Gonis, P. E. A. Turchi and K. Rajan, (Kluwer Academic/Plenum Publishers, 2000) pp. 27-37.

21) M. Niikura, Y. Hagiwara, K. Nagai, K. Tsuzaki and S. Takaki: Proc. International Symposium on Ultrafine Grained Steels (ISUGS 2001, September 20-22, 2001, Fukuoka), ed. by S. Takaki and T. Maki, (The Iron and Steel Institute of Japan, 2001) pp. 26-33.

22) E. M. Lehockey, G. Palumbo, P. Lin and A. M. Brennenstuhl: Scr. Mater. 36 (1997) 1211-1218.

23) D. Stauffer: Introduction to percolation theory. Yoshioka shoten, Japan, (1988) 25. (translated in Japanese)

24) T. Watanabe: Pcoc. NATO Advanced Research Workshop on chemistry and physics of Fracture, ed. by R. M. Latanision and R. H. Jones, (Martinas Nijhoff Pub., NATO ASI series E-130, 1987) pp. 492498. 